\title{
Analysis of Propagation Characteristics for Various Subway Tunnel Scenarios at $28 \mathrm{GHz}$
}

\author{
Chengjian Wang $\mathbb{D}^{1},{ }^{1}$ Wenli Ji, ${ }^{2}$ Guoxin Zheng $\mathbb{D}^{1},{ }^{1}$ and Asad Saleem $\mathbb{D}^{3}$ \\ ${ }^{1}$ Key Laboratory of Specialty Fiber Optics and Optical Access Networks, \\ Join International Research Laboratory of Specialty Fiber Optics and Advanced Communication, Shanghai University, \\ Shanghai 200444, China \\ ${ }^{2}$ System Integration Department, Technical Center, Shanghai Shentong Metro Group Co., Ltd, Shanghai 201103, China \\ ${ }^{3}$ Guangdong Engineering Research Center of Base Station Antennas and Propagation, \\ Key Laboratory of Antennas and Propagation, Shenzhen 518000, China
}

Correspondence should be addressed to Guoxin Zheng; gxzheng@staff.shu.edu.cn

Received 19 April 2021; Revised 25 August 2021; Accepted 28 August 2021; Published 27 September 2021

Academic Editor: Flaminio Ferrara

Copyright (c) 2021 Chengjian Wang et al. This is an open access article distributed under the Creative Commons Attribution License, which permits unrestricted use, distribution, and reproduction in any medium, provided the original work is properly cited.

\begin{abstract}
In order to meet the higher data transmission rate requirements of subway communication services, the millimeter wave (mmWave) broadband communication is considered as a potential solution in $5 \mathrm{G}$ technology. Based on the channel measurement data in subway tunnels, this paper uses ray-tracing (RT) simulation to predict the propagation characteristics of the $28 \mathrm{GHz}$ millimeter wave frequency band in different tunnel scenarios. A large number of simulations based on ray-tracing software have been carried out for tunnel models with different bending radiuses and different slopes, and we further compared the simulation results with the real time measurement data of various subway tunnels. The large-scale and small-scale propagation characteristics of the channel, such as path loss (PL), root mean square delay spread (RMS-DS), and angle spread (AS), for different tunnel scenarios are analyzed, and it was found that the tunnel with a greater slope causes larger path loss and root mean square delay spread. Furthermore, in the curved tunnel, the angle spread of the azimuth angle is larger than that in a straight tunnel. The proposed results can provide a reference for the design of future $5 \mathrm{G}$ communication systems in subway tunnels.
\end{abstract}

\section{Introduction}

In the new era of "intelligent railway mobility," rail transportation communication systems not only need to process critical information, but also need to meet a series of highdata-rate wireless connection services such as on-board high-definition video surveillance [1]. In order to meet the higher data rates, the fifth generation (5G) of mobile communication technology, such as massive multiple-input multiple-output (massive MIMO) and mmWave technology, has been used for rail transit systems [2]. Studying the propagation characteristics of signals in different scenarios and establishing wireless channel models are necessary prerequisites for designing wireless communication systems and transmission technologies [3]. Therefore, studying the propagation characteristics of $5 \mathrm{G}$ frequency band signals in subway tunnel scenarios has a vital importance for operators to develop new communication technologies and design appropriate network architectures.

Early research on propagation characteristics in tunnel scenarios was mainly focused on empty tunnels and lower frequency bands. In [4], the channel measurements were carried out in a high-speed train tunnel, and the PL and RMS-DS at $2.154 \mathrm{GHz}$ were analyzed. It was found that the RMS-DS in the tunnel is mainly below $50 \mathrm{~ns}$ and there exists obvious slow fading in the tunnel. The broadband channel measurements at $980 \mathrm{MHz}$ and $2.450 \mathrm{GHz}$ were carried out on Line 3 of Madrid, Spain, in [5], and the average power and RMS-DS were studied. The research results showed that when the antenna frequency is higher than $2.4 \mathrm{GHz}$ and 
located in the tunnel close to the station, the multipath effect in the subway environment could be significantly reduced. Through the channel measurement in Beijing Metro Line 14 in [6], the PL, RMS-DS, doppler frequency shift, and channel capacity of the tunnels at $2.4 \mathrm{GHz}$ and $5 \mathrm{GHz}$ were analyzed. It is found that the channel characteristics in the tunnel are highly location dependent. The channel measurements from $2.8 \mathrm{GHz}$ to $5 \mathrm{GHz}$ were carried out in a straight arched tunnel, and the relationship between RMS-DS, AS, and distance were studied in [7]. The measurement results showed that when the transceiver distance is more than $100 \mathrm{~m}$, the RMS-DS showed stabilized performance at $2.5 \mathrm{~ns}$, and when the transceiver distance is around $50 \mathrm{~m}$ to $200 \mathrm{~m}$, AS decreased from $10^{\circ}$ to $3^{\circ}$. In order to execute channel measurements in subway tunnels, some scholars use raytracing method to simulate channel propagation characteristics. In $[8,9]$, based on measurement and simulation data, PL of straight tunnel and curved tunnel at $2.4 \mathrm{GHz}$ were studied, respectively, and it was found that the radius of curvature of tunnel had a significant influence on channel characteristics. In curved tunnels, there was an additional loss of received power. In [10], channel characteristics in the tunnel under different frequencies, different transceiver distances, and different cross sections were studied based on the RT simulation results. The results showed that the existence of trains would lead to an additional path loss and channel fluctuation. In addition, in the narrower tunnels, tunnel walls had a more significant effect on the AS results. The channel characteristics at $6 \mathrm{GHz}$ in the tunnel are studied based on measurement and simulation data in [11]. It was found that the normal distribution could better fit the received power. The normal distribution and uniform distribution could fit the azimuth angle of arrival (AOA) of all scenarios.

For the study of millimeter wave propagation characteristics in tunnels, a channel measurement at $31 \mathrm{GHz}$ was carried out in a subway tunnel of Seoul, South Korea, in [12], and the measurement results showed that the delay spread was less than $60 \mathrm{~ns}$ in both straight and curved tunnels. In [13], based on the channel measurement data of Seoul Metro Line 8 , the RT model parameters were analyzed comprehensively, and the PL and RMS-DS of the channel in urban, rural, straight, and curved empty tunnel scenarios at $25 \mathrm{GHz}$ were examined quite efficiently. The channel measurements at $28 \mathrm{GHz}$ were carried out in the same short straight experimental tunnel in [14-16]. The correlation between the RMS-DS, $\mathrm{K}$ factor, and shadow fading parameters was analyzed, and it was found that the AS decreases with the increase of the transceiver distance in [14]. In [15], the channel capacity of $2 \times 2$ and $4 \times 4$ MIMO systems at $28 \mathrm{GHz}$ and the effect of antenna spacing on channel characteristics were studied. In [16], the channel capacity was compared under different polarization modes (horizontal, vertical), and it was found that the capacity of horizontal copolarization is higher than that of vertical copolarization under the assumption of constant signal-to-noise ratio (SNR) in the subway tunnel. The RT method was used to compare the PL and shadow fading parameters of three different antenna settings from $31.5 \mathrm{GHz}$ to $33.5 \mathrm{GHz}$ in straight tunnels with arched cross sections in [17]. A typical straight subway tunnel scene was simulated in [18], and the PL and RMS-DS at $30 \mathrm{GHz}$ were analyzed by using the RT method. In [19], the channel characteristics at $1.4 \mathrm{GHz}$ and $40 \mathrm{GHz}$ in the tunnel were compared based on the simulation results. It was found that when there existed a train in the tunnel, there would be more multipath components, and the propagation characteristics of copolarization and cross polarization performed much differently. Based on the simulation data in [20], the channel characteristics at $37-42.4 \mathrm{GHz}$ in the high-speed railway station was studied, and it was found that the existence of the train had an obvious influence on the AS.

In the existing research, there are relatively few studies at $28 \mathrm{GHz}$ in tunnel scenes, and most of them are concentrated in indoor office, urban, and experimental tunnels. There is a lack of measurements and simulation comparison in the real subway tunnel scenarios, especially the tunnel scenes with real time trains. In addition, the influence of the subway train and its complex scatterers on signal propagation is often ignored. In order to fulfill this gap, this paper studies the channel measurement at $28 \mathrm{GHz}$ in a real subway tunnel environment and calibrates the RT material parameters. Referring to the real tunnel environment, the tunnel models and rail models with different curvature radiuses and slopes are designed. According to the real subway train structure, the metro train model with details such as train chairs and train window is designed. In addition, a comprehensive analysis of various subway tunnel channels is carried out to investigate different aspects of channel propagation.

The rest of this paper is summarized as follows: Section 2 describes the channel measurement in real tunnel environment and RT parameter calibration method. In Section 3, the scenarios and setting of RT simulation are introduced. Section 4 gives the simulation result comparison and complete analysis of channel characteristics. Finally, the conclusion is given in Section 5.

\section{Channel Measurement and RT Parameter Calibration}

2.1. Channel Measurement. As depicted in Figure 1(a), the measurements were conducted in metro Line 7 between Shanghai University and Qihua Rd. in Shanghai, China. The tunnel wall materials are reinforced with concrete. As shown in Figure 1(b), the tunnel can be divided into two sections. One of them is a platform with a length of $28.1 \mathrm{~m}$, and the cross section is rectangular with a height of $5.55 \mathrm{~m}$. Another section is the nonplatform part where the cross section is arched and is $4.96 \mathrm{~m}$ high, as shown in Figure 1(c). Along the driving route, there is a straight tunnel with a length of $20 \mathrm{~m}$, a curved tunnel with a length of $100 \mathrm{~m}$, and a long straight tunnel with a length of over $400 \mathrm{~m}$, respectively.

The measurement system is illustrated in Figure 2. It is mainly composed of Agilent E8257D signal source (transmitter) and Ceyear 4024G spectrum analyzer (receiver). Both transmitting antenna $(\mathrm{Tx})$ and receiving antenna $(\mathrm{Rx})$ are ultra-wideband omnidirectional antennas, and the highprecision rubidium clocks are used to ensure clock synchronization as shown in Figure 3. 


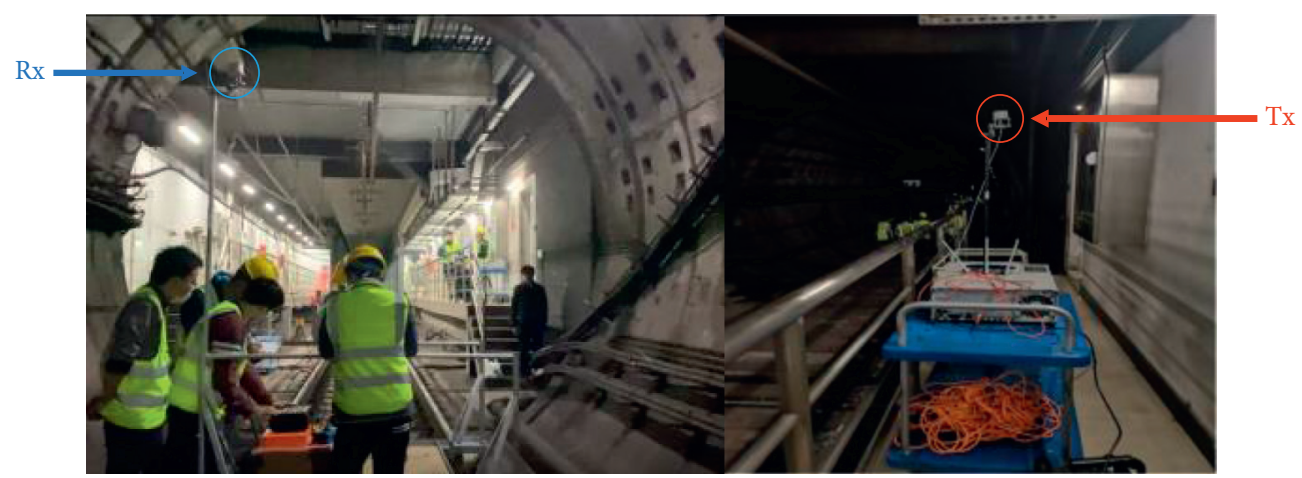

(a)

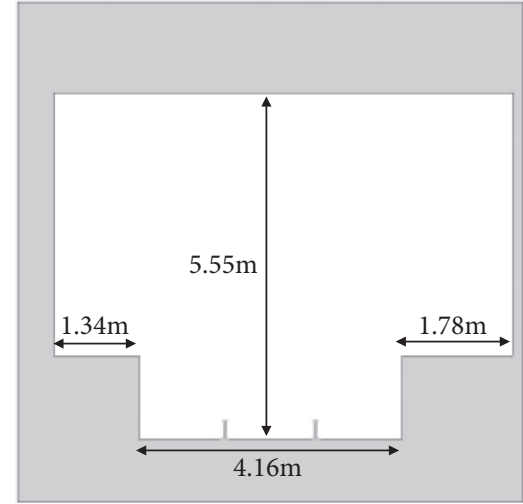

(b)

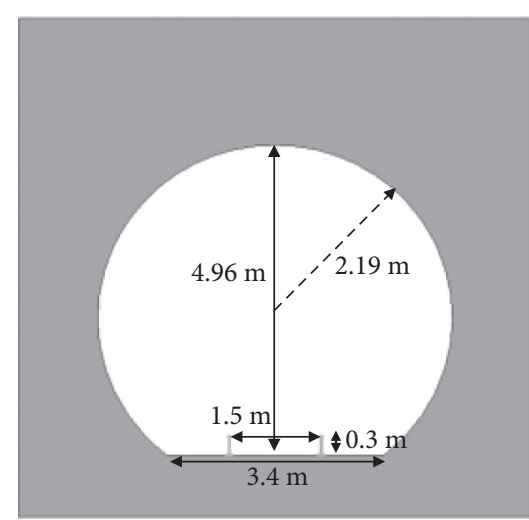

(c)

Figure 1: The measurement environment: (a) measurement subway tunnel; (b) platform cross section; (c) nonplatform cross section.

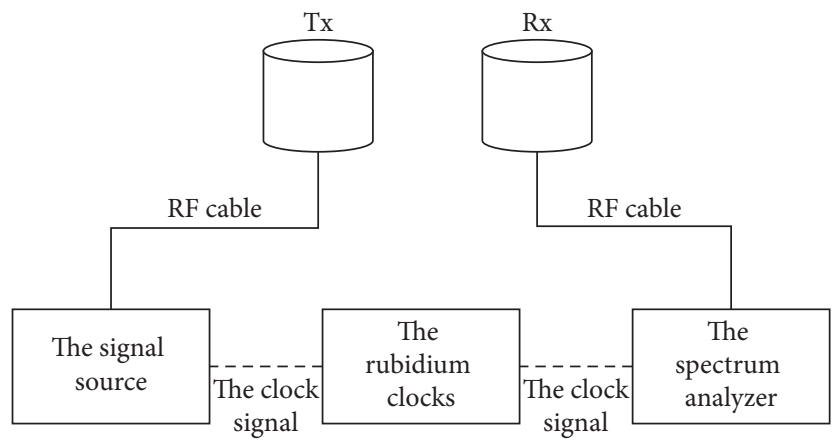

Figure 2: Measurement system.
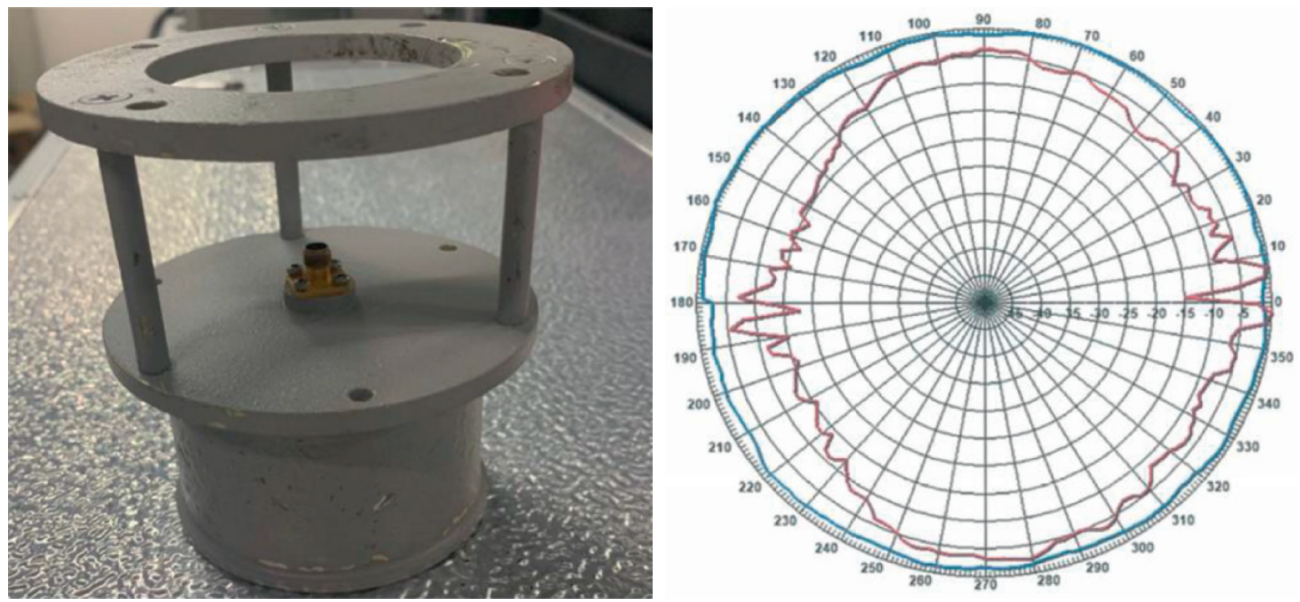

Figure 3: Ultra-wideband omnidirectional antenna. 
In the measurements, the transmitter is located at the end of the tunnel platform, close to the tunnel wall, and the height of the transmitting antenna is $3.1 \mathrm{~m}$, as shown in Figure 4(a). The receiver is located on the railcar in the center of the tunnel, and the receiving antenna is $2.25 \mathrm{~m}$ high. The position of the transmitter remains unchanged, and the measurement distance is $500 \mathrm{~m}$. The input power and the frequency are considered as $10 \mathrm{dBm}$ and $28 \mathrm{GHz}$, respectively. As the railcar moves, the receiver gradually moves away from the transmitter. We have considered a total of 79 test points, and at each test point, the spectrum analyzer reads and records the received power of the signal. The positions of the transmitting and receiving antennas are shown in Figure 4(b). When the transceiver distance is about $100 \mathrm{~m}$, the sampling interval is $2 \mathrm{~m}$. The interval from $100 \mathrm{~m}$ to $300 \mathrm{~m}$ is $10 \mathrm{~m}$, and the interval from $300 \mathrm{~m}$ to $500 \mathrm{~m}$ is $20 \mathrm{~m}$.

2.2. Ray-Tracing Parameter Calibration. Based on the received power from the field measurement, the material property parameters in the RT simulation, such as the material roughness, relative permittivity, and conductivity, can be calibrated. The RT simulation tool used in this article is Wireless Insite (WiSE). The 3D model of the subway tunnel in the measurement is reconstructed, as shown in Figure 5. The designs of frequency and positions of antennas in the simulation are the same as in the measurement field. For the concrete and metal materials in simulations, we had set the initial roughness, conductivity, and permittivity and then compared the simulated PL results with the measurement data. According to the compared results, we keep adjusting the parameters until there is a high degree of match between the simulation and measurement results. Figure 6 shows the comparison between the simulated PL and the measurement results after adjusting the material property parameters several times. It can be found that, at most test points, the simulated PL results are very close to the measurement data. Because the field environment is highly complex and there are more reflections, the simulation and measurement results are slightly different at individual test points.

The classic floating-intercept PL model in [21] is described as follows:

$$
\mathrm{PL}(d)=\beta+10 \alpha \lg \left(\frac{d}{d_{0}}\right)+X_{\sigma}(\mathrm{d} b),
$$

where $\alpha$ is the slope of the PL model and $d_{0}$ is the reference transceiver distance, which is $1 \mathrm{~m}$ in this paper. $\beta$ is the model intercept, which represents the PL value when the transceiver distance is the reference distance, and $X_{\sigma}$ is a Gaussian random variable with standard deviation of $\sigma$. Based on this, PL results of simulation and measurement are fitted, respectively, and their PL models are shown in Figure 6. It can be found that the PL models of the measurement and simulation match well. The parameters of PL models are shown in Table 1, where $\alpha$ and $\beta$ are basically the same. The comparison results confirm that the RT simulation parameters are very close to the values in the real environment, indicating that the corrected material parameters can be used to simulate the channel propagation characteristics in different subway tunnel environments. At this time, the material parameters are shown in Table 2.

\section{Channel Propagation Characteristics Based on the RT Method}

3.1. Simulation Scenarios Description. Referring to the tunnel of Shanghai Line 7, this paper designs tunnel models with a straight tunnel and tunnels with different curvature radiuses and different slopes and sets up a metro train model with reference to trains of Line 7, as shown in Figure 7(a).

All tunnel models designed in this paper are divided into two sections, $l 1$ and $l 2$. The $l 1$ section is a short straight tunnel with a length of $20 \mathrm{~m}$, while $l 2$ section is a tunnel with different structure in different scenarios and has a length of $200 \mathrm{~m}$. As shown in Figure 7(a), 12 of the straight tunnel model is a straight tunnel. In the curved tunnel model, $l 2$ is a curved tunnel with a radius of $r$, and two $r$ values are designed, $500 \mathrm{~m}$ and $300 \mathrm{~m}$, respectively. In the tunnel model with a slope, $l 2$ is an inclined tunnel with a slope of $\theta$, and two $\theta$ values are designed, $2^{\circ}$ and $3^{\circ}$, respectively. The cross sections of all tunnel models are arched, as shown in Figure $1(\mathrm{c})$. The metro train model is $24.4 \mathrm{~m}$ long, $3 \mathrm{~m}$ wide, and $3.8 \mathrm{~m}$ high. The interior of the train is shown in Figures 7(b) and 7(c). There are 10 doors, 31 glass windows, 8 chairs, and several vertical handrails inside.

This paper considers three types of subway tunnel scenarios: subway tunnel scenarios with different curvature radiuses (Case.2 and Case.3), subway tunnel scenarios with different slopes (Case.4 and Case.5), and subway tunnel scenario with the train (Case.6), as shown in Table 3. At the same time, Table 3 shows the length, radius, and slope of the tunnel model for each scenario. Table 4 shows the train model and the dimensions of the internal objects.

3.2. Simulation Settings. In the simulation, the frequency of the transmitting and receiving antennas is set to $28 \mathrm{GHz}$, the bandwidth is $100 \mathrm{MHz}$, both the transmitting and receiving antennas are omnidirectional antennas, and the input power is $10 \mathrm{dBm}$.

The position settings of the receiving and transmitting antennas in the three scenarios are also different, as shown in Figure 8. In tunnel scenarios with different curvature radiuses and slopes (Case.1-Case.5), as shown in Figure 8(a), the transmitting antenna is located in the center of the tunnel cross section with a height of $2.48 \mathrm{~m}$. The first receiving antenna is $10 \mathrm{~m}$ away from the transmitting antenna, and then a receiving antenna is placed every $5 \mathrm{~m}$ until the transceiver distance of $210 \mathrm{~m}$. There are a total of 41 receiving positions, and all receiving antennas are located in the center of the cross section of the tunnel with a height of $2.48 \mathrm{~m}$. In the tunnel scene with the train (Case.6), as shown in Figure $8(\mathrm{~b})$, the transmitting antenna is close to the left tunnel wall, $2.5 \mathrm{~m}$ away from the midline of the tunnel cross section and $3 \mathrm{~m}$ high. In Case. 6 , three positions of receiving antennas are considered, all located in the midline of the tunnel cross section. Rx1 is located at the top of the train and 


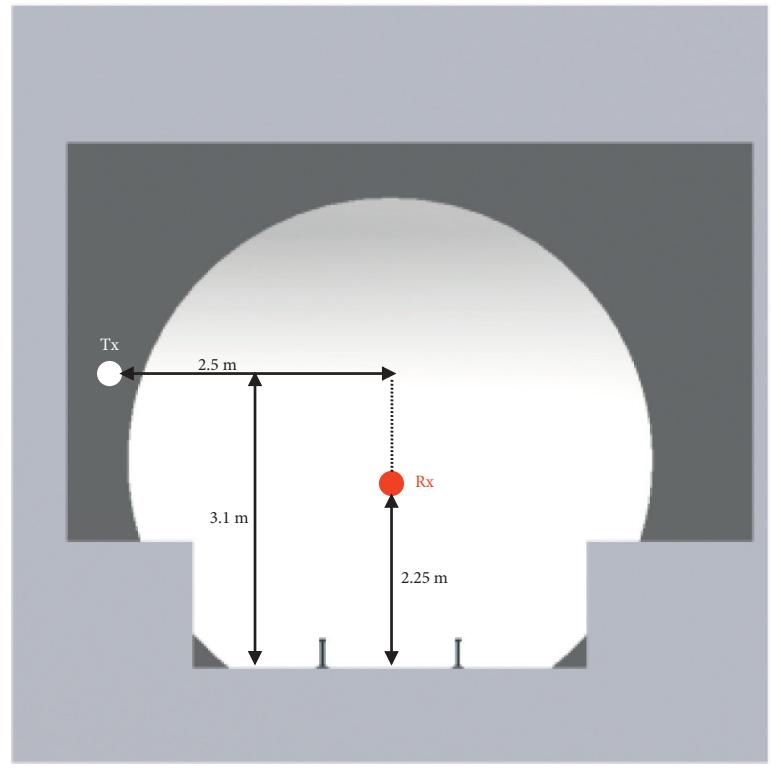

(a)

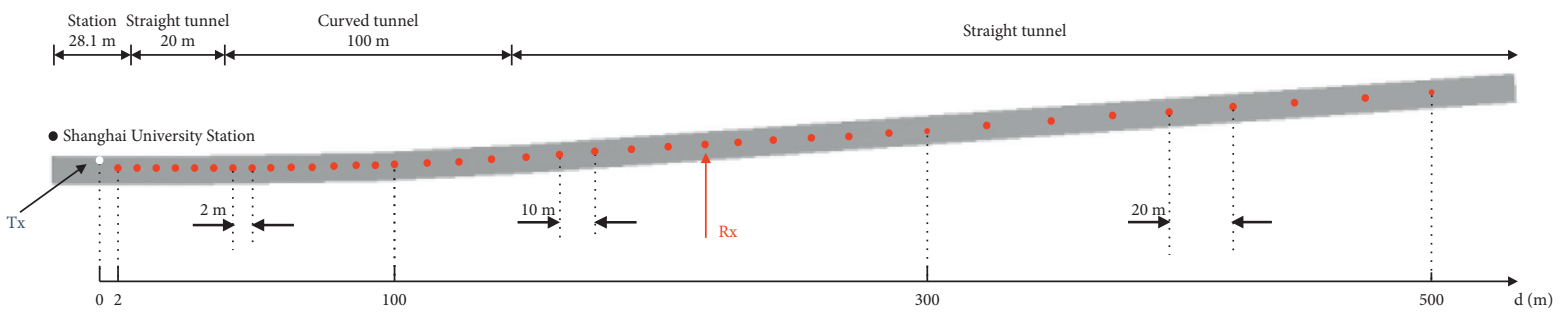

(b)

FIgURE 4: Transceiver settings in the measurement: (a) the cross section of the measurement tunnel; (b) the positions of Tx and Rx.

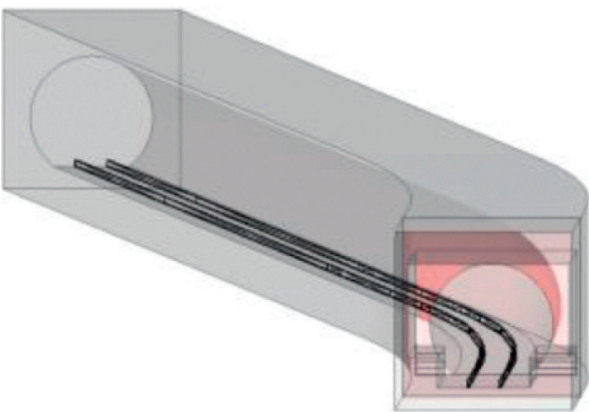

Figure 5: 3D model of the subway tunnel.

is $4.3 \mathrm{~m}$ high. $\mathrm{Rx} 2$ is located in front of the train and is $1.8 \mathrm{~m}$ high. $\mathrm{Rx} 3$ is located inside the carriage and is $4.3 \mathrm{~m}$ high. At a distance of $15 \mathrm{~m}$, the subway train starts moving away from the transmitting antenna, and the simulations are carried out every $5 \mathrm{~m}$ until the train moves to a distance of $200 \mathrm{~m}$ from the transmitting antenna.

In the RT simulation, this paper considers four materials: concrete, metal, glass, and plastic. Table 5 shows the parameter settings of all materials. The parameters of concrete and metal 1 use the calibration results in Section 2.2, and other material parameter settings use the values recommended by ITU (International Telecommunication Union)-

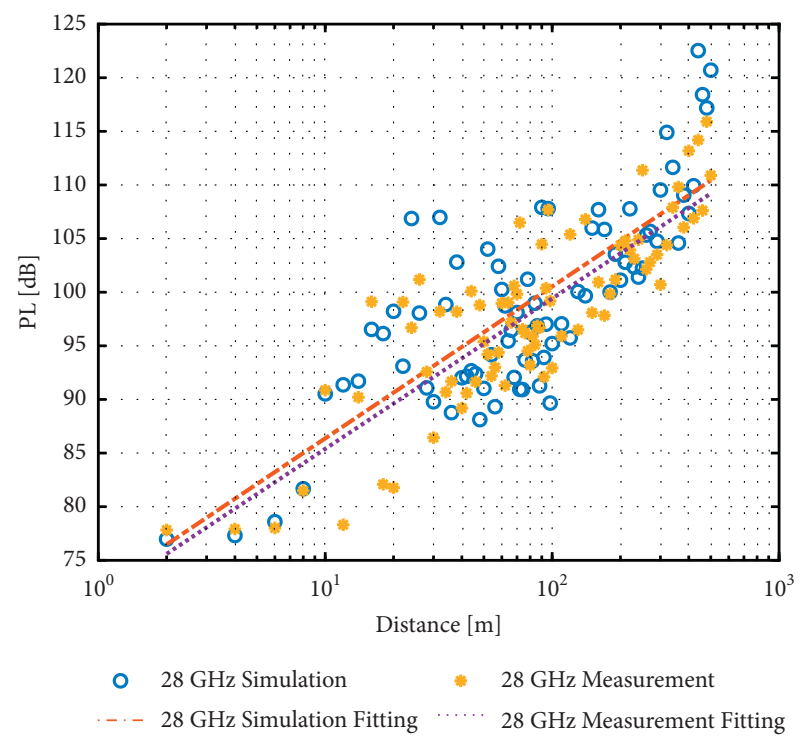

Figure 6: Comparison of PL results between measurement and RT simulation at $28 \mathrm{GHz}$.

R P.2040 [22]. In addition, we set the number of reflections to 15 , the number of transmission to 2 , the spacing of rays to $0.1^{\circ}$ and assume that no more than 100 rays are received. 
TABLe 1: PL model parameters at $28 \mathrm{GHz}$.

\begin{tabular}{lccr}
\hline & $\alpha$ & $\beta$ & $\sigma$ \\
\hline Measurement & 1.4016 & 71.3789 & 4.4641 \\
RT simulation & 1.4154 & 72.2181 & 5.5509 \\
\hline
\end{tabular}

TABLE 2: Material property parameters after calibration.

\begin{tabular}{lcccccc}
\hline & Material & Frequency $(\mathrm{GHz})$ & Relative permittivity & Conductivity $(\mathrm{S} / \mathrm{m})$ & Thickness $(\mathrm{m})$ & Roughness $(\mathrm{m})$ \\
\hline Tunnel wall & Concrete & 28 & 5.31 & 0.48 & 0.5 & 0.005 \\
Rail & Metal 1 & 28 & - & - & 0.05 & 0.0001 \\
\hline
\end{tabular}
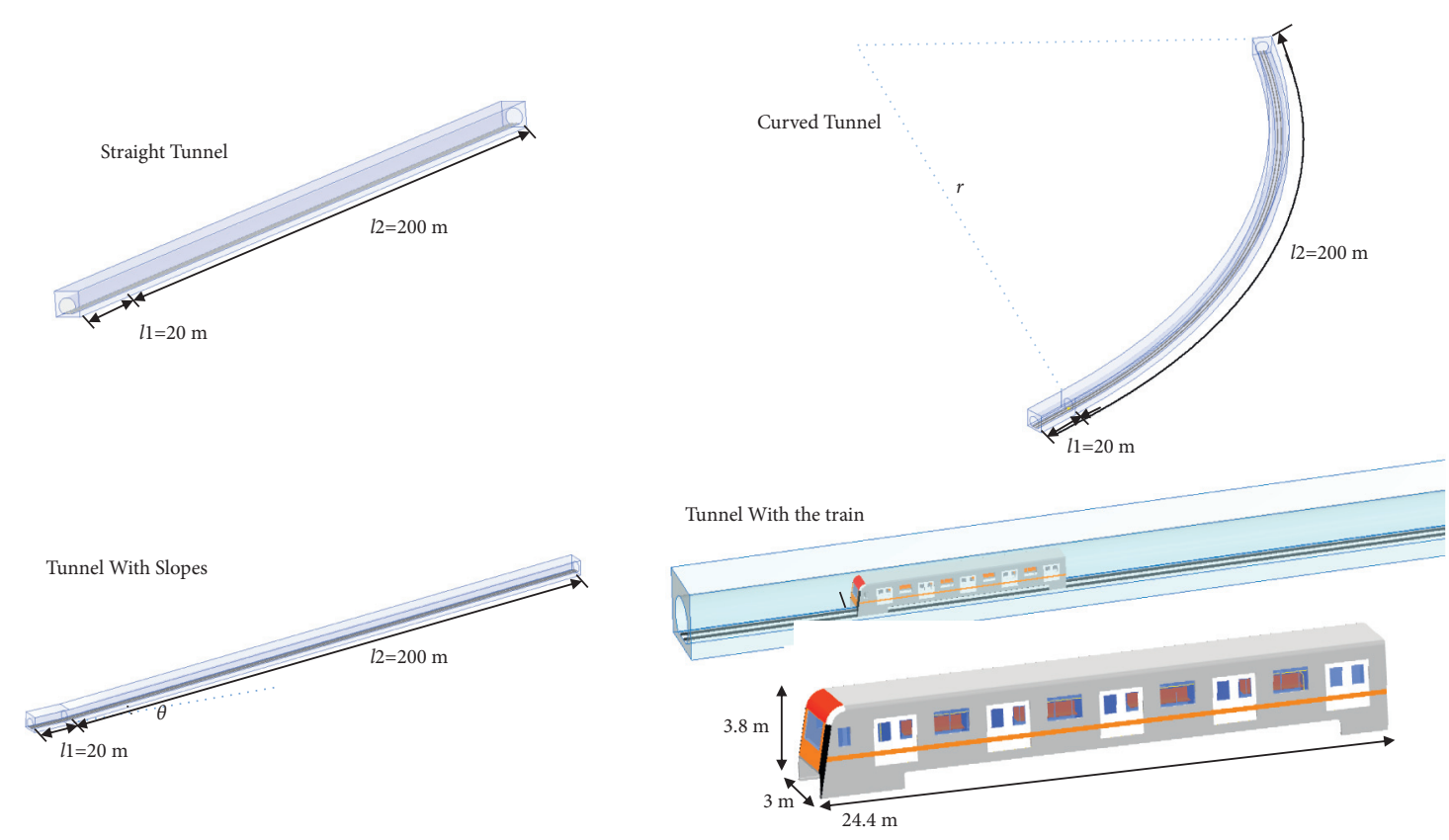

(a)

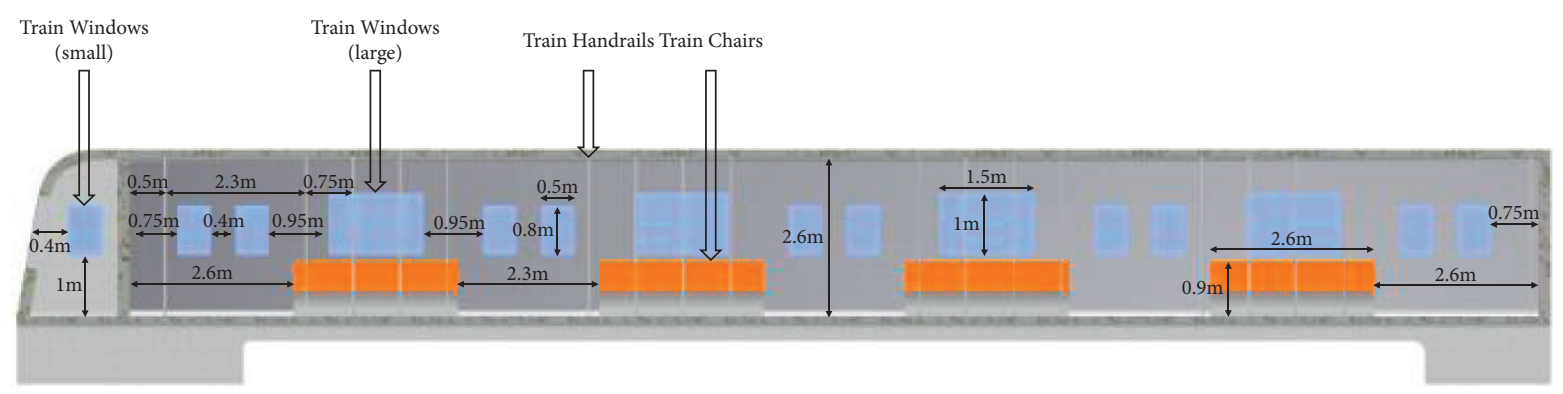

(b)

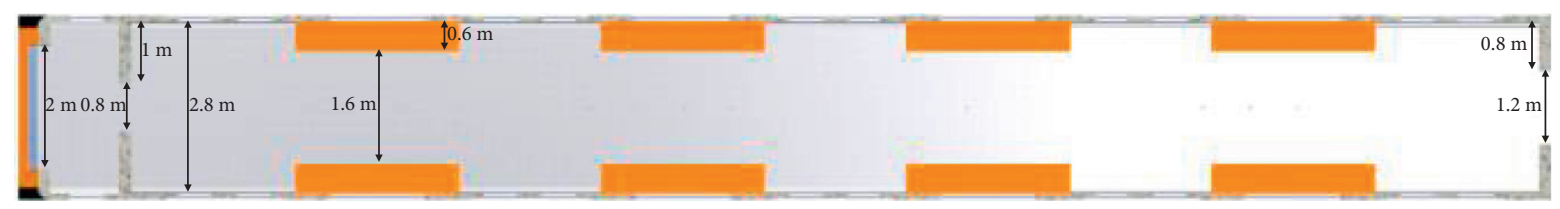

(c)

FIgURE 7: 3D models of the subway tunnels and the metro train: (a) 3D models of tunnels; (b) longitudinal section view of the metro train model; (c) cross section view of the metro train model. 
TABLE 3: Scenarios and their tunnel models.

\begin{tabular}{|c|c|c|c|c|c|c|}
\hline Scenario & Tunnel model & $d_{l 1}(\mathrm{~m})$ & $d_{l 2}(\mathrm{~m})$ & $r(\mathrm{~m})$ & $\theta^{\circ}$ & Metro train \\
\hline Case.1 & Straight tunnel & 20 & 200 & - & - & Without \\
\hline Case. 2 & Curved tunnel 1 & 20 & 200 & 500 & - & Without \\
\hline Case. 3 & Curved tunnel 2 & 20 & 200 & 300 & - & Without \\
\hline Case. 4 & Sloped tunnel 1 & 20 & 200 & - & 2 & Without \\
\hline Case. 5 & Sloped tunnel 2 & 20 & 200 & - & 3 & Without \\
\hline Case. 6 & Straight tunnel & 20 & 200 & - & - & With \\
\hline
\end{tabular}

TABle 4: The metro train model and internal object size.

\begin{tabular}{lcccc}
\hline Model & Amount & Length $(\mathrm{m})$ & Width $(\mathrm{m})$ & Height $(\mathrm{m})$ \\
\hline Train carriage & - & 24.4 & 3 & 2 \\
Window (train head) & 1 & 0.05 & 0.05 & 1.2 \\
Window (large) & 22 & 1.5 & 0.05 & 1 \\
Window (small) & 8 & 0.5 & 0.05 & 0.8 \\
Train chair & 8 & 2.6 & 0.05 \\
Train handrail & 17 & 0.05 & 0.9 \\
\hline
\end{tabular}

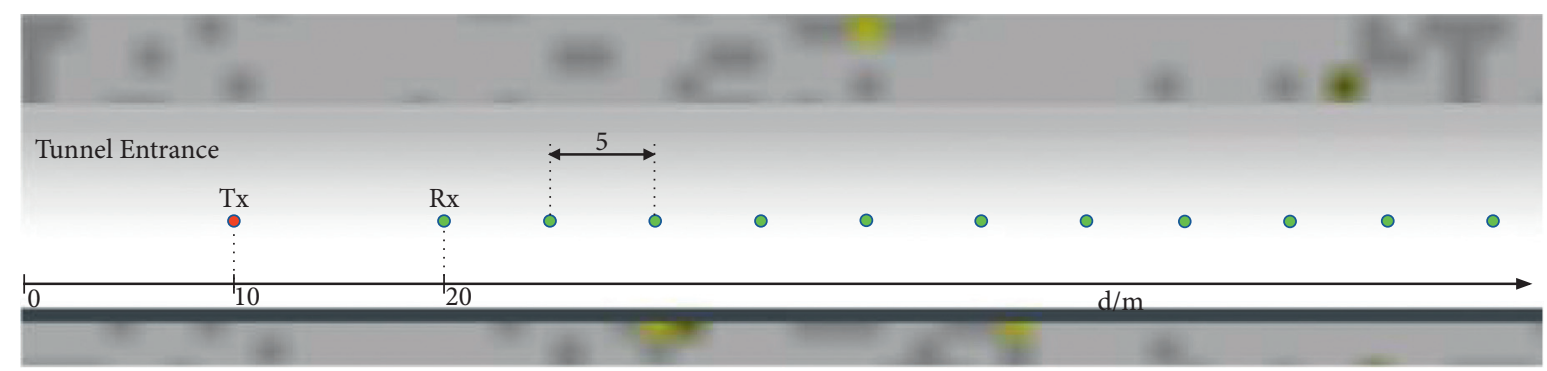

(a)
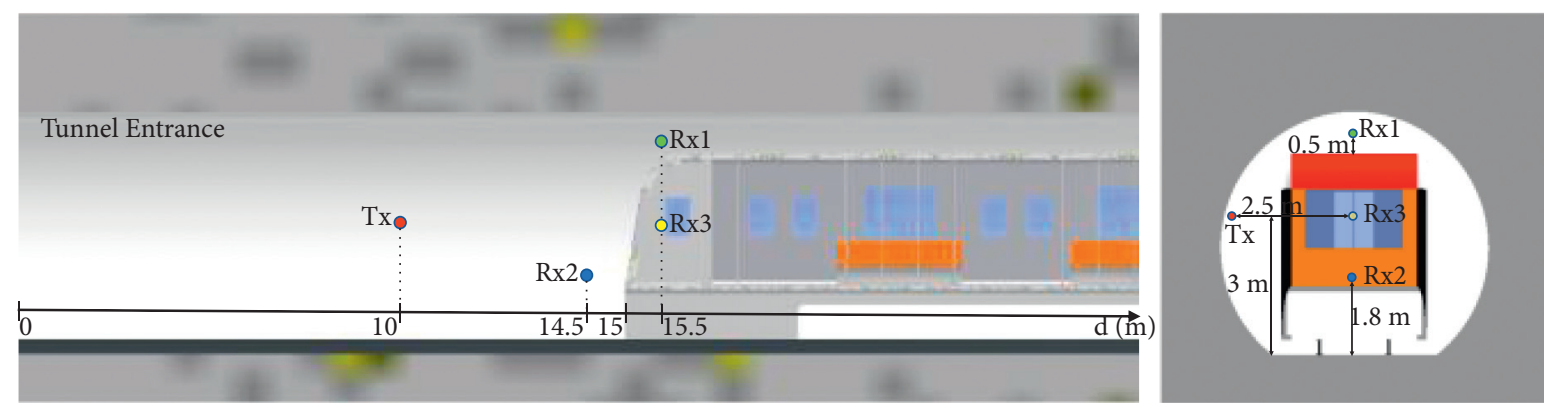

(b)

FIGURE 8: Transceiver antenna position settings: (a) transceiving antennas' settings in Case.1-Case.5; (b) transceiving antennas' settings in Case.6.

TABle 5: Parameter settings of all materials.

\begin{tabular}{lcccccc}
\hline Object & Material & Frequency $(\mathrm{GHz})$ & Relative permittivity & Conductivity $(\mathrm{S} / \mathrm{m})$ & Thickness $(\mathrm{m})$ & Roughness $(\mathrm{m})$ \\
\hline Tunnel wall & Concrete & 28 & 5.31 & 0.48 & 0.5 & 0.005 \\
Rail & Metal 1 & 28 & - & - & 0.05 & 0.0001 \\
Carriage & Metal 2 & 28 & - & 0.23 & 0 \\
Windows & Glass & 28 & 6.27 & - & 0.03 & 0.05 \\
Chairs & Plastic & 28 & - & - & 0 \\
\hline
\end{tabular}




\section{Simulation Results and Analysis}

4.1. Subway Tunnel Scenarios with Different Curvature Radiuses (Case.1, Case.2, and Case.3). The simulation results are executed according to (1), and the PL models of Case.1, Case.2, and Case. 3 are achieved, as shown in Figure 9. The PL model parameters are shown in Table 6 . It can be found that, with the decrease of the tunnel curvature radius, the PL value at the same transceiver distance increases. This is because the smaller the tunnel curvature radius is, the sooner the line-ofsight (LOS) component of the signal will disappear, and the more the attenuation of the non-line-of-sight (NLOS) component will increase. When the curvature radius is $500 \mathrm{~m}$, the slope of the PL model is close to that of the PL model of free space. In addition, the slope of the floatingintercept PL model of the straight tunnel is smaller than that of the indoor environment in [23] and the urban environment in [24] at $28 \mathrm{GHz}$. This is mainly because the waveguide effect of the tunnel reduces the power attenuation. Moreover, the obstacles in the subway tunnel are fewer than those in the indoor or urban environment, which reduces the obstruction to signal propagation.

The expression for calculating the RMS-DS in [25] is as follows:

$$
\begin{aligned}
\bar{t} & =\frac{\sum_{i=1}^{N} P_{i} t_{i}}{P}, \\
t_{\mathrm{RMS}-\mathrm{DS}} & =\sqrt{\frac{\sum_{i=1}^{N} p_{i} t_{i}^{2}}{P}-\bar{t}^{2}},
\end{aligned}
$$

where $P$ represents the received power at this point and $P_{i}$ and $t_{i}$ are the received power and time delay of the $i$-th path, respectively. Based on this, the RMS-DS results of Case.1, Case.2, and Case. 3 can be obtained, as shown in Figure 10, and the statistical parameters are shown in Table 7. It can be found that the RMS-DS mean of Case. 3 is the largest while the RMS-DS mean of Case.1 is the smallest. This is because, with the decrease of the tunnel curvature radius, multipath signals need to go through more reflections before they can be received, leading to the increase of path difference between multipath signals and the increase of RMS-DS.

The relationship of estimating the angle spread (AS) in [26] is as follows:

$$
\begin{aligned}
\theta_{\mathrm{AS}} & =\sqrt{-2 \ln \left(\left|\frac{\sum_{i=1}^{N} e^{\left(j \theta_{i}\right)} P_{n}}{P}\right|\right)}, \\
\mu_{\theta} & =\arg \sum_{i=1}^{N} e^{\left(j \theta_{i}\right)} P_{i},
\end{aligned}
$$

where $P$ is the received power at this point; $P_{i}$ and $\theta_{i}$ are the received power and the direction of arrival or departure of the $i$-th path, respectively; and $\mu_{\theta}$ is the power weighted mean angle. Based on this, the AS of Case.1, Case.2, and Case. 3 can be obtained. In Figure 11, ASA, ESA, ASD, and ESD are the AS of the azimuth angle of arrival (AOA), the

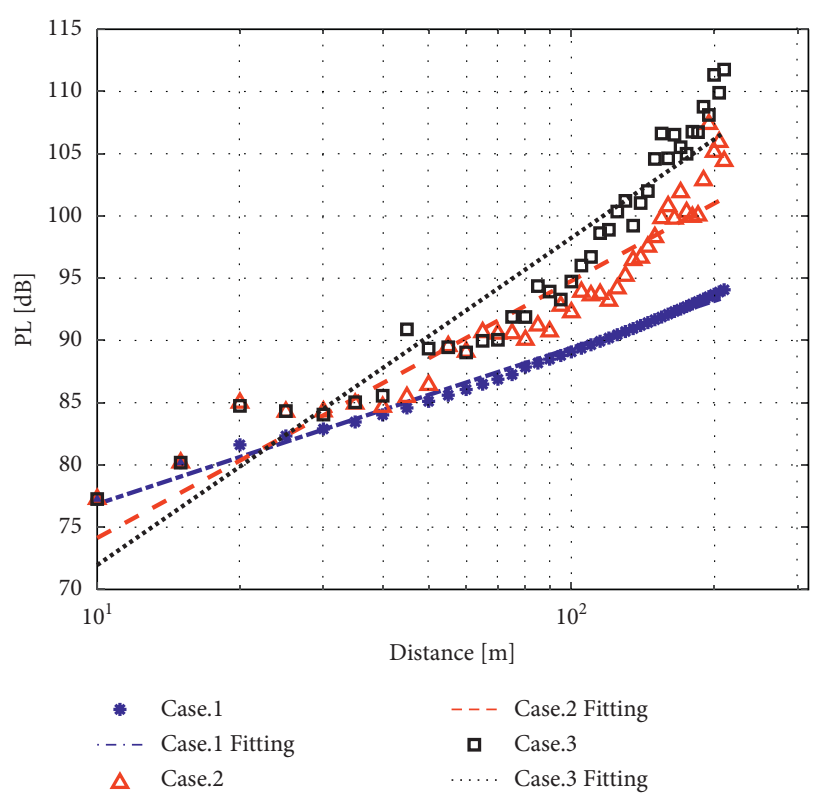

Figure 9: PL models of Case.1, Case.2, and Case.3.

Table 6: PL model parameters of Case.1, Case.2, and Case.3.

\begin{tabular}{lccc}
\hline Scenario & $\alpha$ & $\beta$ & $\sigma$ \\
\hline Case.1 & 1.2539 & 64.3227 & 0.4357 \\
Case. 2 & 2.0647 & 53.4887 & 2.4111 \\
Case. 3 & 2.6285 & 45.6747 & 2.8547 \\
\hline
\end{tabular}

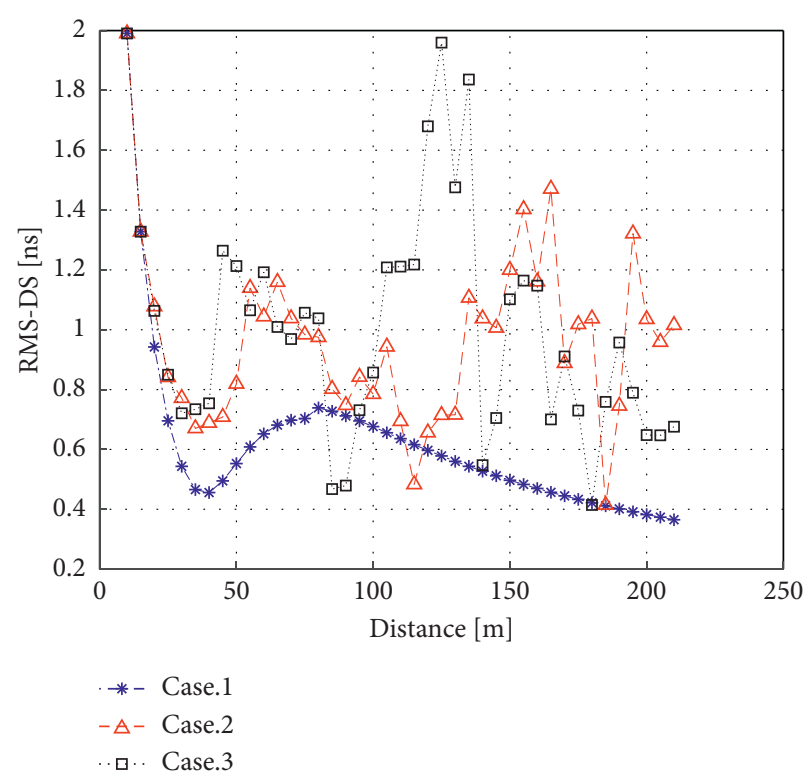

Figure 10: RMS-DS of Case.1, Case.2, and Case.3.

elevation angle of arrival (EOA), the azimuth angle of departure (AOD), and the elevation angle of departure (EOD) for each scenario. The AS statistical parameters of Case.1, Case.2, and Case. 3 are shown in Table 8. It can be found that both the ASA and the ASD of Case.1, Case.2, and Case. 3 are 
TABLe 7: RMS-DS statistical parameters of Case.1, Case.2, and Case.3.

\begin{tabular}{lccc}
\hline Scenario & Mean value $(\mathrm{ns})$ & Standard deviation $(\mathrm{ns})$ & Maximum value $(\mathrm{ns})$ \\
\hline Case.1 & 0.6127 & 0.2816 & 1.9904 \\
Case. 2 & 0.9620 & 0.2870 & 1.9904 \\
Case. 3 & 1.0066 & 0.3840 & 1.9904 \\
\hline
\end{tabular}
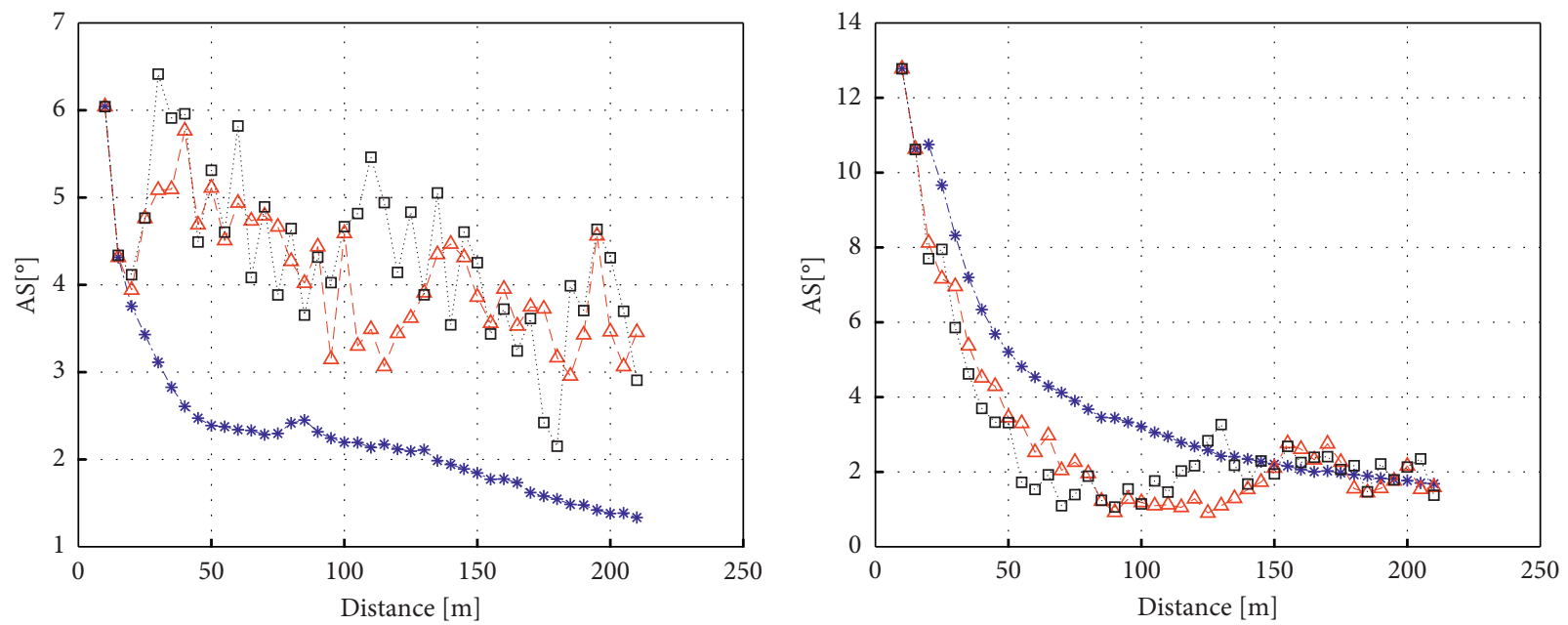

*- Case. 1

$\Delta-$ Case. 2

* - Case. 1

... Case. 3

(a)

- $\Delta$ - Case. 2

a. Case. 3

(b)
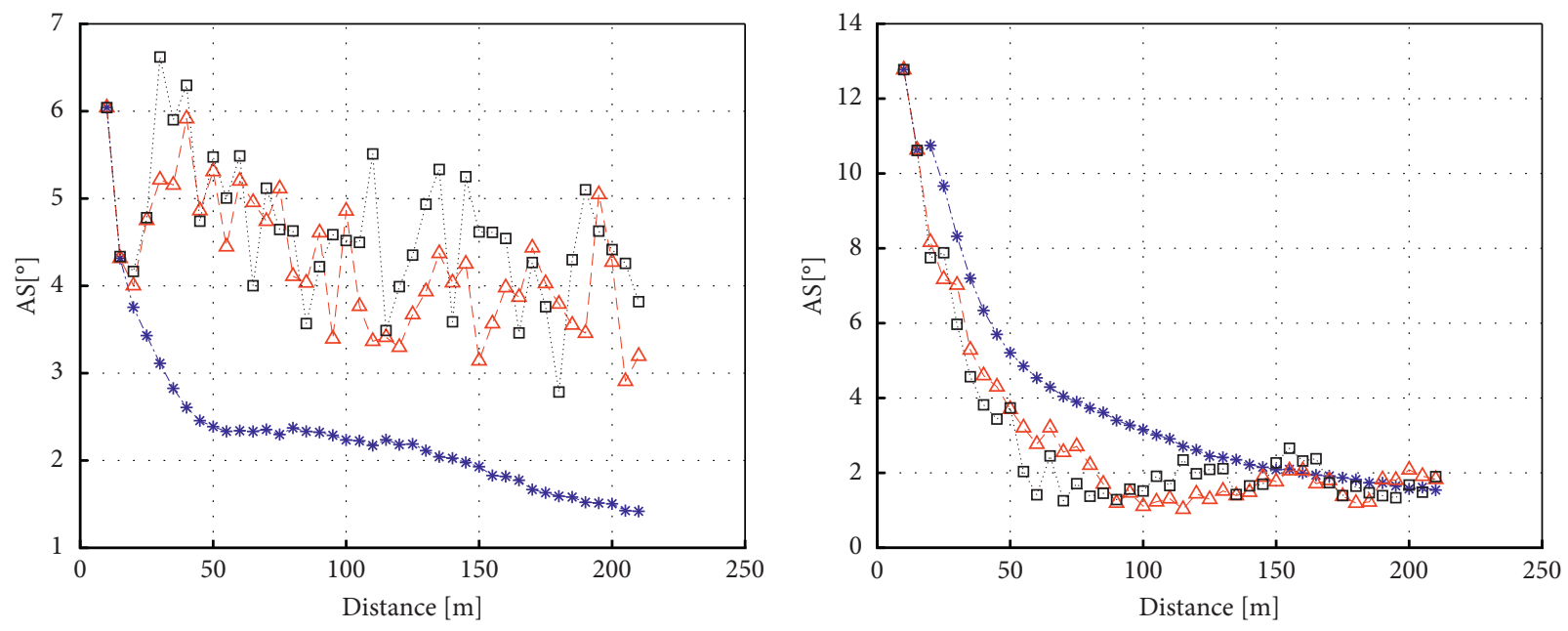

$*-$ Case. 1

$*$ - Case. 1

- $\Delta-$ Case. 2

$\Delta-$ Case. 2

口.. Case. 3

घ. Case. 3

(c)

(d)

FIgure 11: AS of Case.1, Case.2, and Case.3: (a) ASA; (b) ESA; (c) ASD; (d) ESD.

TABLE 8: AS statistical parameters of Case.1, Case.2, and Case.3.

\begin{tabular}{ccccc}
\hline & Scenario & Mean value $\left(^{\circ}\right)$ & Standard deviation $\left(^{\circ}\right)$ & Maximum value $\left(^{\circ}\right)$ \\
\hline \multirow{3}{*}{ ASA } & Case.1 & 2.2736 & 0.8727 & 6.0414 \\
& Case. 2 & 4.1302 & 0.7485 & 6.0414 \\
& Case.3 & 4.3734 & 0.9364 & 6.4141 \\
\hline
\end{tabular}


TABle 8: Continued.

\begin{tabular}{lcccc}
\hline & Scenario & Mean value $\left(^{\circ}\right)$ & Standard deviation $\left(^{\circ}\right)$ & Maximum value $\left(^{\circ}\right)$ \\
\hline \multirow{3}{*}{ ESA } & Case.1 & 3.9980 & 2.8030 & 12.7750 \\
& Case.2 & 2.9388 & 2.6591 & 12.7750 \\
& Case.3 & 2.9593 & 2.5359 & 12.7750 \\
\multirow{3}{*}{ ASD } & Case.1 & 2.3052 & 0.8515 & 6.0413 \\
& Case.2 & 4.2536 & 0.7626 & 6.0413 \\
\hline \multirow{2}{*}{ ESD } & Case.3 & 4.6255 & 0.8016 & 6.6207 \\
& Case.1 & 3.9461 & 2.8404 & 12.7749 \\
& Case.2 & 2.9514 & 2.6505 & 12.7749 \\
\hline
\end{tabular}

about $10^{\circ}$. When the transceiver distance exceeds $15 \mathrm{~m}$, the ASA and ASD of Case. 2 and Case. 3 are greater than those of Case.1. The reason is that, in curved tunnels, multipath signals need to be reflected more times before they can be received, leading to the increase of AS. Both the ESA and the ESD of Case.1, Case.2, and Case. 3 are about $15^{\circ}$. When the transceiver distance is less than $100 \mathrm{~m}$, both the ESA and the ESD of Case.1, Case.2, and Case. 3 decrease monotonously, and those of Case. 2 and Case. 3 are smaller than those of Case.1. When the transceiver distance is more than $100 \mathrm{~m}$, the ESA and ESD of Case.1, Case.2, and Case. 3 gradually tend to be the same. Until the transceiver distance is $150 \mathrm{~m}$, they are basically the same. It can be seen that the curvature radius of the tunnel has a more obvious influence on the AS of azimuth angle than that of elevation angle.

4.2. Subway Tunnel Scenarios with Different Curvature Radiuses (Case.1, Case.4, and Case.5). Based on (1), the PL models of Case.1, Case.4, and Case. 5 can be achieved, as shown in Figure 12. The PL model parameters of Case.1, Case.4, and Case. 5 are shown in Table 9. It can be found that, as the slope increases, the intercept of the PL model increases. This is mainly because when the transceiver distance is less than $20 \mathrm{~m}$ in the tunnel scenario with a larger slope, the signal is reflected more times from the transmitting to the receiving side, leading to a faster attenuation rate of the NLOS component, and this makes the path loss larger. It is worth noting that, with the increase of the transceiver distance, the influence of slope on the propagation of the NLOS component decreases, so the attenuation rate of the NLOS component becomes slow and gradually becomes consistent with that of the straight tunnel. When the transceiver distance is $200 \mathrm{~m}$, the PL values of Case.1, Case.4, and Case. 5 have been found to be very close.

The RMS-DS results of Case.1, Case.4, and Case. 5 are shown in Figure 13, and the statistical parameters are shown in Table 10. It can be found that the RMS-DS mean values of Case. 4 and Case. 5 scenarios are larger than that of Case.1. The main reason is that, with the increase of tunnel slope, the path difference between multipath signals becomes larger, leading to the increase of RMS-DS. After the transceiver distance is more than $150 \mathrm{~m}$, the RMS-DS values of Case. 4 and Case.1 are almost the same. This shows that the multipath component difference caused by the distance between

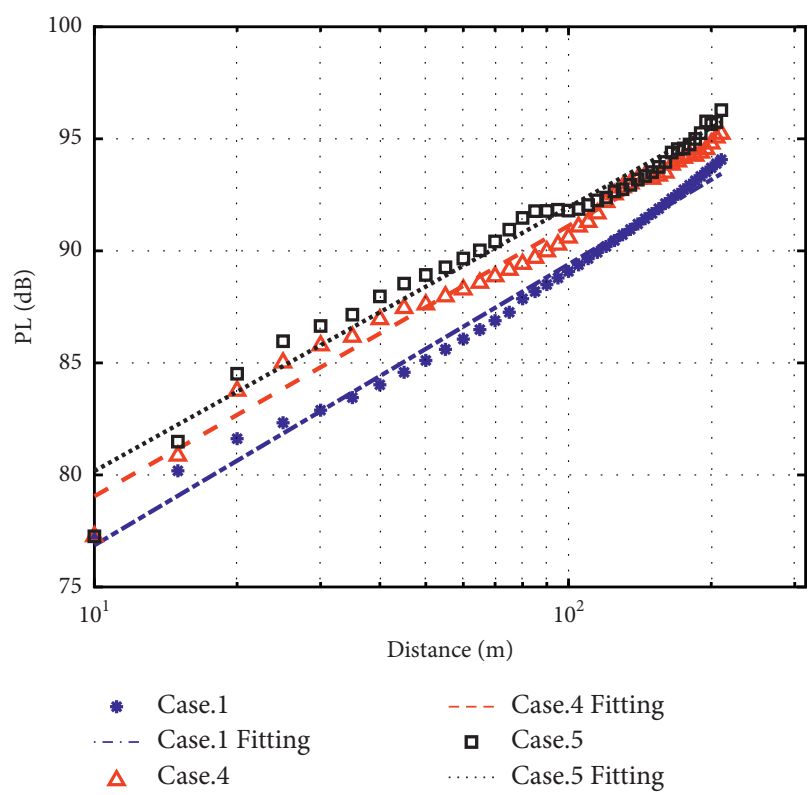

Figure 12: PL models of Case.1, Case.4, and Case.5.

Table 9: PL model parameters of Case.1, Case.4, and Case.5.

\begin{tabular}{lccc}
\hline & $\alpha$ & $\beta$ & $\sigma$ \\
\hline Case.1 & 1.2539 & 64.3227 & 0.4357 \\
Case.4 & 1.2067 & 66.9799 & 0.5148 \\
Case.5 & 1.1777 & 68.3946 & 0.6725 \\
\hline
\end{tabular}

the transmitter and the receiving antenna can be ignored when the transceiver distance is large, which is consistent with the conclusion of that in [27].

The AS results of Case.1, Case.4, and Case. 5 are shown in Figure 14, and the statistical parameters are shown in Table 11. It can be found that the AS in the tunnel shows a downward trend with the increase of the transceiver distance, which is similar to the conclusion in [14]. When the transceiver distance is about $50 \mathrm{~m}$, the AS values of Case. 4 and Case. 5 are both smaller than that of Case.1. This means that when the distance between receiving and transmitting antennas is relatively close, in the tunnel with slope, some multipath signals experience more reflection, resulting in increased loss, so they cannot be received, and the AS decreases. When the transceiver distance is more than $150 \mathrm{~m}$, 


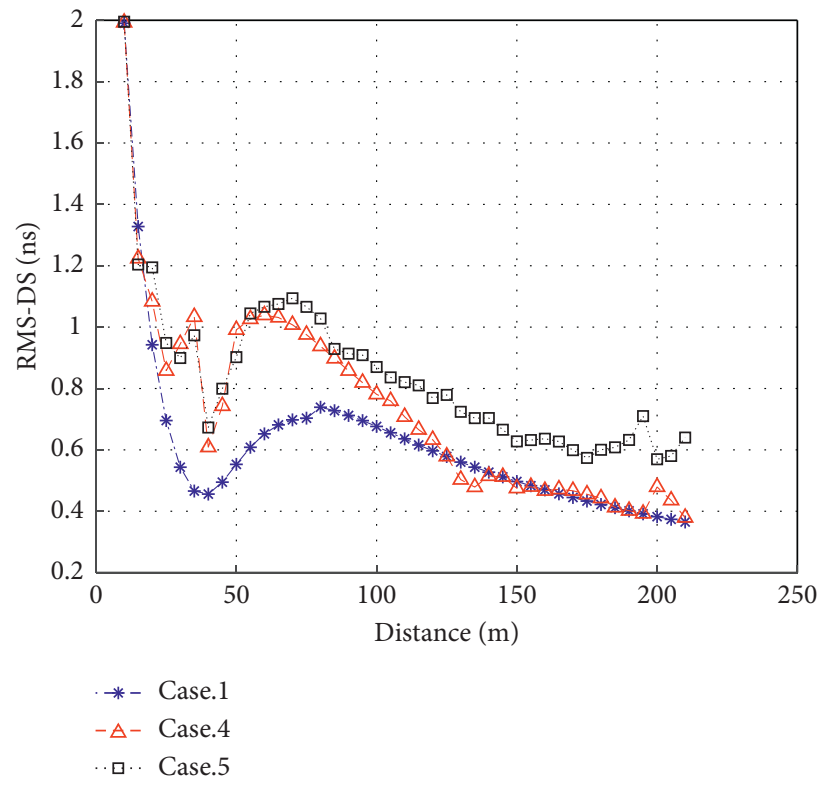

Figure 13: RMS-DS of Case.1, Case.4, and Case.5.

Table 10: RMS-DS statistical parameters of Case.1, Case.4, and Case.5.

\begin{tabular}{lccc}
\hline & Mean value $(\mathrm{ns})$ & Standard deviation $(\mathrm{ns})$ & Maximum value (ns) \\
\hline Case.1 & 0.6127 & 0.2816 & 1.9904 \\
Case.4 & 0.7308 & 0.3179 & 1.9925 \\
Case.5 & 0.8399 & 0.2610 & 1.9953 \\
\hline
\end{tabular}
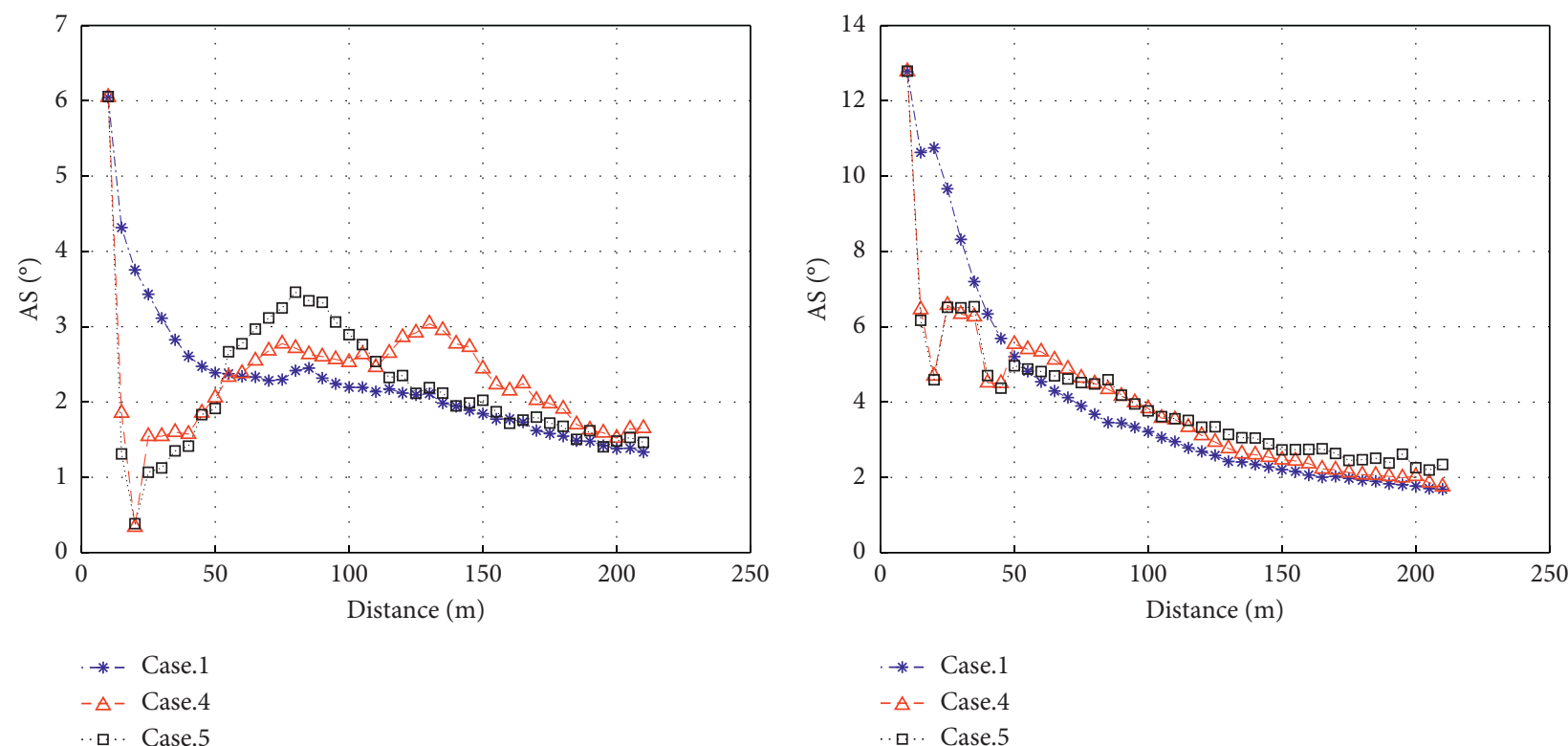

(a)

(b)

Figure 14: Continued. 


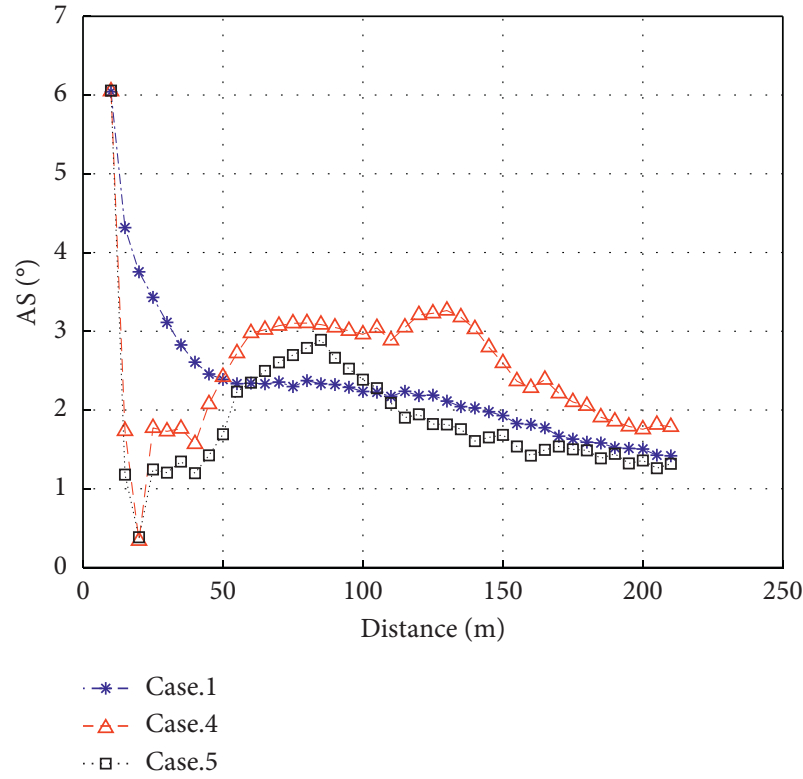

(c)

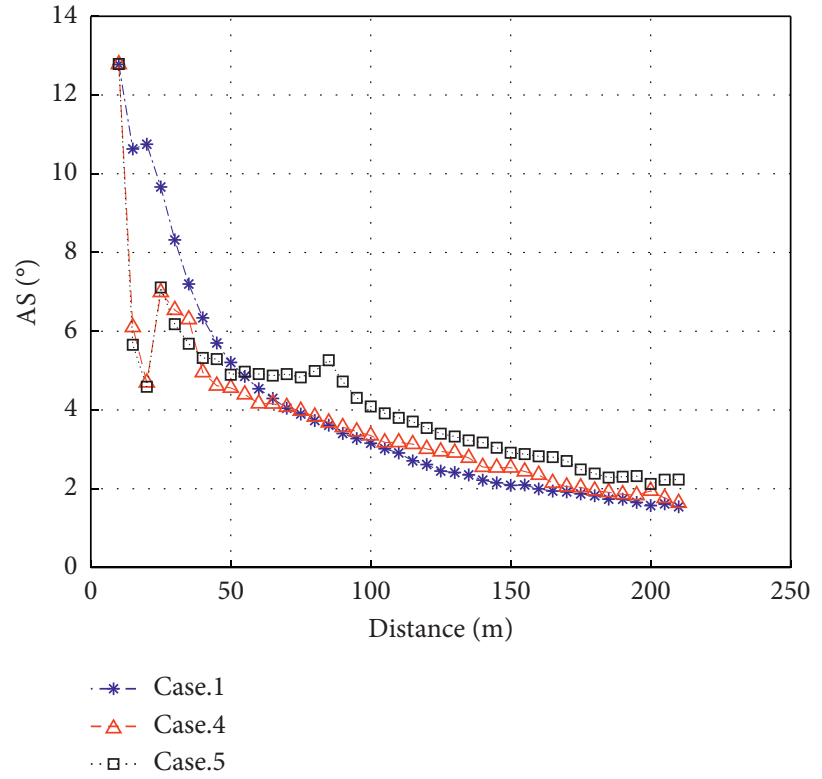

(d)

Figure 14: AS of Case.1, Case.4, and Case.5: (a) ASA; (b) ESA; (c) ASD; (d) ESD.

TABle 11: AS statistical parameters of Case.1, Case.4, and Case.5.

\begin{tabular}{|c|c|c|c|c|}
\hline & Scenario & Mean value $\left({ }^{\circ}\right)$ & Standard deviation $\left({ }^{\circ}\right)$ & Maximum value $\left({ }^{\circ}\right)$ \\
\hline \multirow{3}{*}{ ASA } & Case.1 & 2.2736 & 0.8727 & 6.0414 \\
\hline & Case. 4 & 2.2906 & 0.8204 & 6.0478 \\
\hline & Case. 5 & 2.1763 & 0.9508 & 6.0559 \\
\hline \multirow{3}{*}{ ESA } & Case. 1 & 3.9980 & 2.8030 & 12.7750 \\
\hline & Case. 4 & 3.8657 & 2.0380 & 12.7804 \\
\hline & Case. 5 & 3.9993 & 1.8711 & 12.7873 \\
\hline \multirow{3}{*}{ ASD } & Case.1 & 2.3052 & 0.8515 & 6.0413 \\
\hline & Case. 4 & 2.5397 & 0.8620 & 6.0478 \\
\hline & Case. 5 & 1.8775 & 0.8671 & 6.0560 \\
\hline \multirow{3}{*}{ ESD } & Case.1 & 3.9461 & 2.8404 & 12.7749 \\
\hline & Case. 4 & 3.6311 & 2.0132 & 12.7803 \\
\hline & Case. 5 & 4.1223 & 1.8845 & 12.7874 \\
\hline
\end{tabular}

the AS values of three scenarios tend to be the same. This proves that the influence of slope on signal propagation is reduced when the transceiver distance is far.

4.3. Subway Tunnel Scenario with the Train (Case.6). In Case.6, the PL results of $\mathrm{Rx}$ at different positions are shown in Figure 15. Throughout the measurement distance, the PL of Rx2 is always less than those of Rx1 and Rx3. This is because $\mathrm{Rx} 2$ is located in front of the train driver's cab and can receive the signals reflected from the tunnel walls and the surface of the train. The PL of $\mathrm{Rx} 3$ is always the highest, mainly because $\mathrm{Rx} 3$ is located inside the metro train carriage. When the signal reaches the receiving end, it needs to penetrate the train windows, resulting in extra energy loss. When the transceiver distance is $200 \mathrm{~m}$, the loss through the train windows is about $15 \mathrm{~dB}$. The PL model parameters of $\mathrm{Rx} 1, \mathrm{Rx} 2$, and $\mathrm{Rx} 3$ are shown in Table 12 . It can be found that the $\mathrm{PL}$ results of $\mathrm{Rx} 1$ and $\mathrm{Rx} 2$ gradually tend to be the same with the increase of the transceiver distance, indicating that the influence of the train on signal propagation gradually decreases with the increase of the transceiver distance.

The RMS-DS results of $\mathrm{Rx} 1, \mathrm{Rx} 2$, and $\mathrm{Rx} 3$ are shown in Figure 16, and the RMS-DS statistical parameters are shown in Table 13. The average value of the RMS-DS of Rx3 is significantly greater than those of $\mathrm{Rx} 1$ and $\mathrm{Rx} 2$. This is mainly because $\mathrm{Rx} 3$ can receive the signals reflected from the rear of the train, which increases the path difference between multipath signals. Further, it can be seen that when the antenna is located inside the carriage, the reflection environment is more complicated. The RMS-DS of Rx2 is slightly larger than that of $\mathrm{Rx} 1$, mainly because $\mathrm{Rx} 2$ can receive the signals reflected by the surface of the train.

The AS results of $\mathrm{Rx} 1, \mathrm{Rx} 2$, and $\mathrm{Rx} 3$ are shown in Figure 17, and the statistical parameters are shown in Table 14. When the transceiver distance is more than $60 \mathrm{~m}$, 


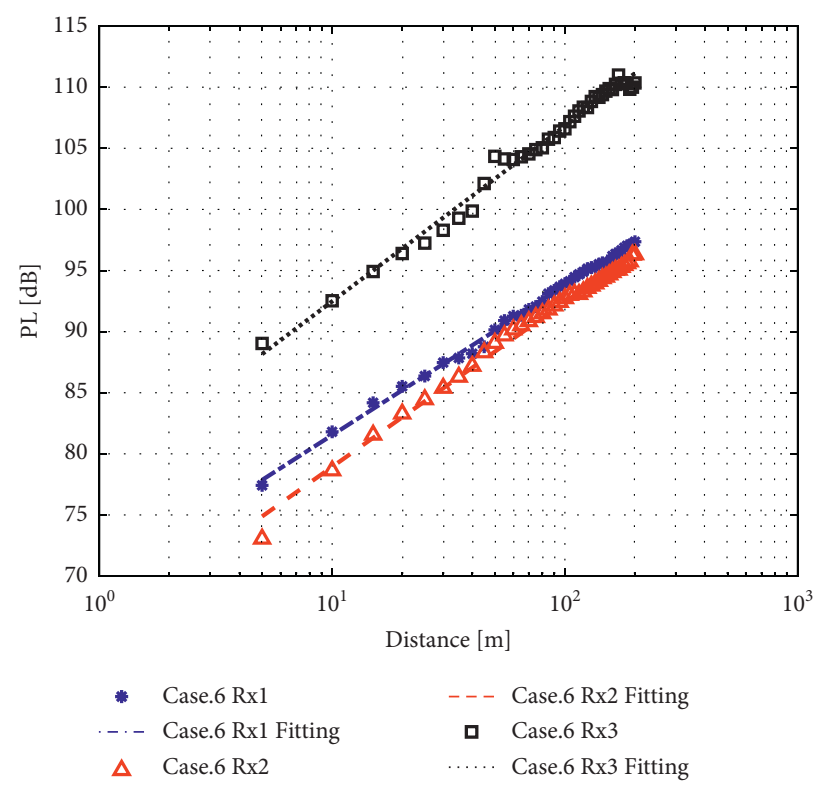

Figure 15: PL model of Rx1, Rx2, and Rx3 in Case.6.

TABle 12: PL model parameters of $\mathrm{Rx} 1, \mathrm{Rx} 2$, and $\mathrm{Rx} 3$ in Case.6.

\begin{tabular}{lccr}
\hline & $\alpha$ & $\beta$ & $\sigma$ \\
\hline $\mathrm{Rx} 1$ & 1.2800 & 69.3339 & 0.2606 \\
$\mathrm{Rx} 2$ & 1.3478 & 65.4581 & 0.4733 \\
$\mathrm{Rx} 3$ & 1.4344 & 78.1328 & 0.6242 \\
\hline
\end{tabular}

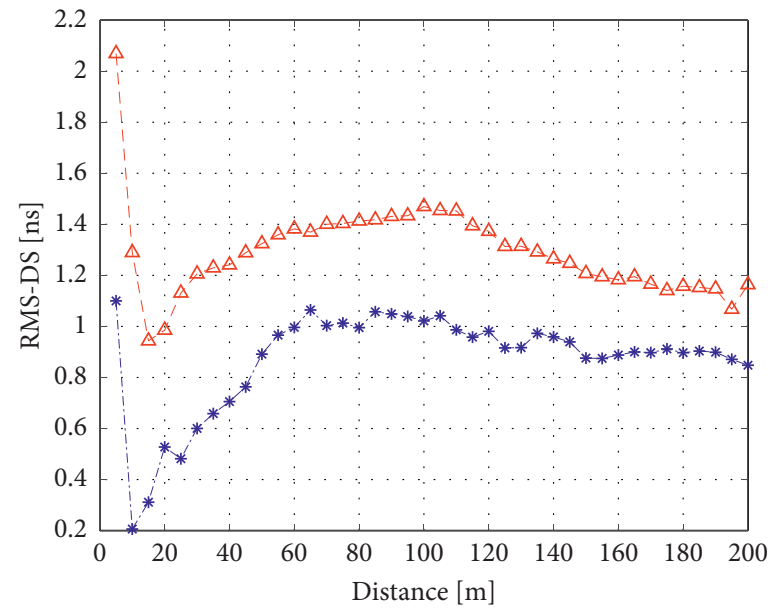

*- Case. $6 \mathrm{Rx} 1$

$-\Delta-$ Case. $6 \mathrm{Rx} 2$

(a)

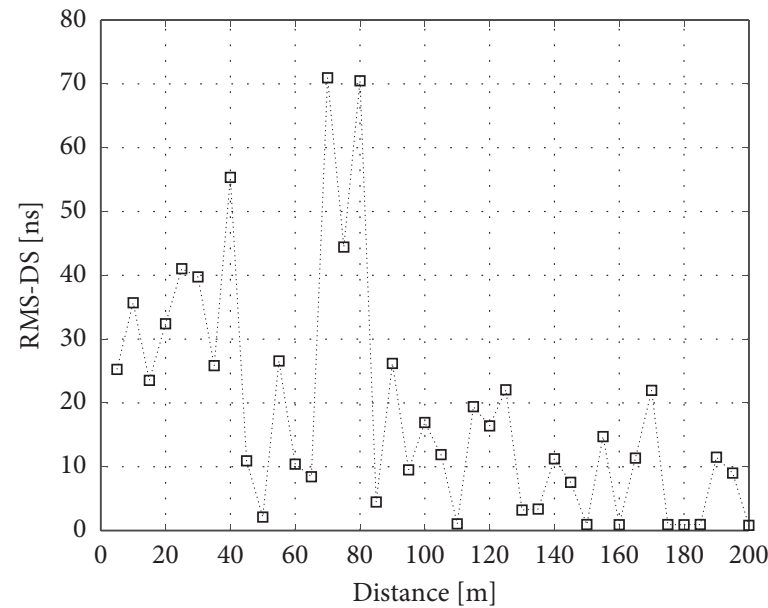

๑.. Case.6 Rx3

(b)

Figure 16: RMS-DS of Rx1, Rx2, and Rx3 in Case.6: (a) RMS-DS of Rx1 and Rx2; (b) RMS-DS of Rx3.

TABLe 13: RMS-DS statistical parameters of $\mathrm{Rx} 1, \mathrm{Rx} 2$, and $\mathrm{Rx} 3$ in Case.6.

\begin{tabular}{lccc}
\hline & Mean value (ns) & Standard deviation (ns) & Maximum value (ns) \\
\hline $\mathrm{Rx} 1$ & 0.8722 & 0.2002 & 1.1010 \\
$\mathrm{Rx} 2$ & 1.2917 & 0.1811 & 2.0691 \\
$\mathrm{R} 3$ & 18.7639 & 18.2750 & 70.9541 \\
\hline
\end{tabular}



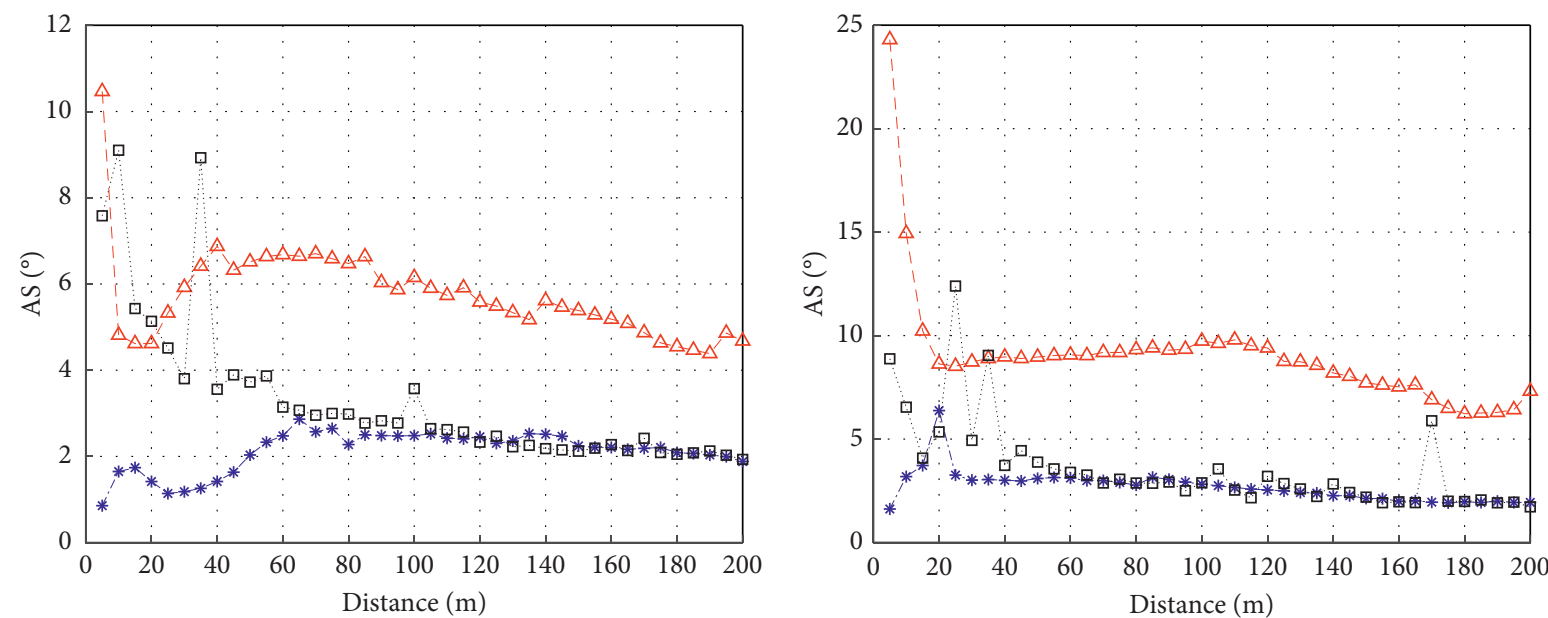

*- Case.6 Rx1

$-\Delta-$ Case.6 Rx2

*- Case. $6 \mathrm{Rx} 1$

$-\Delta-$ Case.6 Rx2

.. . Case. $6 \mathrm{Rx} 3$

(a)

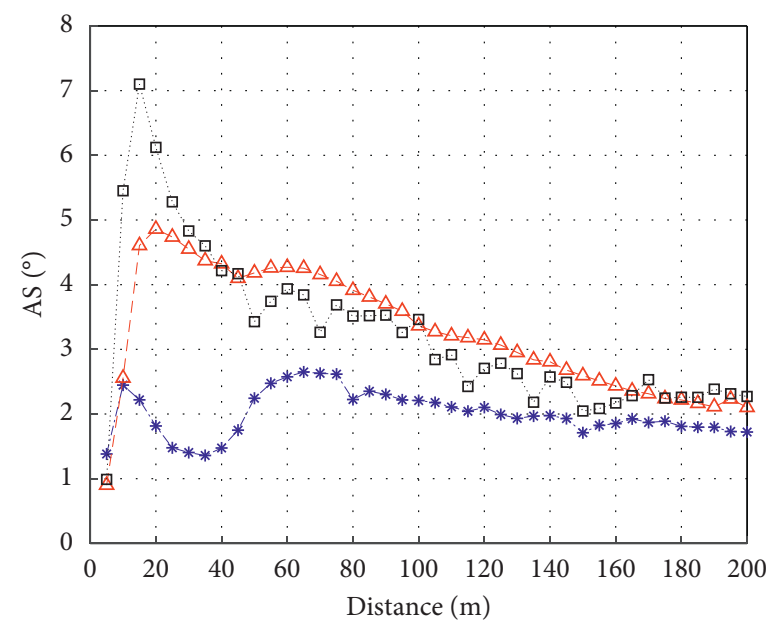

(b)

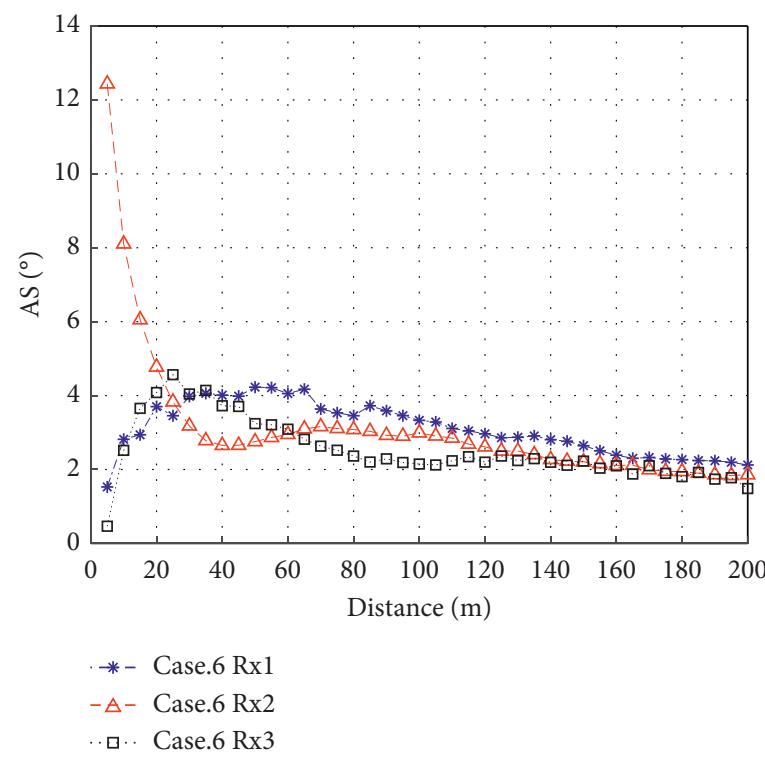

(c)

(d)

Figure 17: AS of Rx1, Rx2, and Rx3 in Case.6: (a) ASA; (b) ESA; (c) ASD; (d) ESD.

TABLE 14: AS statistical parameters of $\mathrm{Rx} 1, \mathrm{Rx} 2$, and $\mathrm{Rx} 3$ in Case.6.

\begin{tabular}{|c|c|c|c|c|}
\hline & Rx position & Mean value $\left({ }^{\circ}\right)$ & Standard deviation $\left({ }^{\circ}\right)$ & Maximum value $\left({ }^{\circ}\right)$ \\
\hline \multirow{3}{*}{ ASA } & $\mathrm{Rx} 1$ & 2.1179 & 0.4708 & 2.8648 \\
\hline & $\mathrm{Rx} 2$ & 5.7471 & 1.0729 & 10.4650 \\
\hline & $\mathrm{Rx} 3$ & 3.2883 & 1.7460 & 9.1013 \\
\hline \multirow{3}{*}{ ESA } & $\mathrm{Rx} 1$ & 2.6873 & 0.7845 & 6.3774 \\
\hline & $\mathrm{Rx} 2$ & 9.0175 & 2.8920 & 24.3014 \\
\hline & $\mathrm{Rx} 3$ & 3.5855 & 2.2327 & 12.3933 \\
\hline \multirow{3}{*}{ ASD } & $\mathrm{Rx} 1$ & 1.9994 & 0.3479 & 2.6501 \\
\hline & $\mathrm{Rx} 2$ & 3.2748 & 0.9472 & 4.8599 \\
\hline & $\mathrm{Rx} 3$ & 3.2585 & 1.2386 & 7.1010 \\
\hline \multirow{3}{*}{ ESD } & $\mathrm{Rx} 1$ & 3.0997 & 0.7104 & 4.2279 \\
\hline & $\mathrm{Rx} 2$ & 3.1050 & 1.9069 & 12.4340 \\
\hline & $\mathrm{Rx} 3$ & 2.5169 & 0.8346 & 4.5651 \\
\hline
\end{tabular}


the AS of Rx1 and Rx 3 gradually tends to be the same. This is because, with the increase of transceiver distance, the signals reflected from the rear of the carriage become weaker and weaker, leading to a consistent multipath signal distribution of $\mathrm{Rx} 1$ and $\mathrm{Rx} 3$. However, $\mathrm{Rx} 2$ can always receive the strong signals reflected from the train surface, so the AS of arrival of $\mathrm{Rx} 2$ is always larger than those of $\mathrm{Rx} 1$ and $\mathrm{Rx} 3$. In addition, with the increase of the transceiver distance, the ASD and ESD of Rx1, Rx2, and $\mathrm{Rx} 3$ tend to be the same.

\section{Conclusions}

Based on the RT simulation method, this paper studies the propagation characteristics at $28 \mathrm{GHz}$ in a variety of subway tunnel scenarios. The actual measurement data is used to calibrate the property parameters of the materials in order to execute simulations. In addition, tunnel models with different curvature radiuses, different slopes, and a train are established. The PL, RMS-DS, and AS results of three different tunnel scenarios are analyzed. The main results are as follows:

(1) For subway tunnel scenarios with different curvature radiuses, with the increase of transceiver distance, in tunnels with a smaller radius, the LOS component of the signal will disappear earlier, and the attenuation of NLOS components will accelerate, resulting in the increase of PL and RMS-DS. The curvature radius of the tunnel has a more obvious effect on the AS of the arrival angle. The smaller the curvature radius of the tunnel is, the larger the ASA and ASD will be.

(2) On the premise of conforming to the subway tunnel construction standards, for subway tunnel scenarios with different slopes, the difference of slopes will have a significant impact on the channel characteristics within a transceiver distance of $100 \mathrm{~m}$. The tunnel with a larger slope will have larger PL and RMS-DS results. When the transceiver distance is about $50 \mathrm{~m}$, the ASA and ESA in the subway tunnel with a slope are obviously smaller than those in the straight tunnel. When the transceiver distance is more than $150 \mathrm{~m}$, the influence of the slope on channel characteristics gradually decreases.

(3) For the subway tunnel scenario with the metro train, when the receiving antenna is located in front of the train, it can receive the signals reflected by the train surface, so the PL is smaller, and the RMS-DS, ASA, and ESA are all increased. When the receiving antenna is located inside the carriage, the energy loss caused by the signal penetrating the train window is about $15 \mathrm{~dB}$. Because the signals reflected from the rear of the train can be received, the multipath distribution is more complicated, and the RMS-DS is significantly larger than those in other scenarios.

These results can provide reference for the design of $5 \mathrm{G}$ communication systems in subway tunnels for future challenges.

\section{Data Availability}

The data used to support the findings of this study are available from the corresponding author upon request.

\section{Conflicts of Interest}

The authors declare that there are no conflicts of interest regarding the publication of this paper.

\section{Acknowledgments}

This work was supported by the National Natural Foundation of China under Grant 61871261 and Scientific Research Project of Shanghai Shentong Metro Group Co., Ltd. (JS-KY19R031).

\section{References}

[1] K. Guan, G. Li, T. Kurner et al., "On millimeter wave and THz mobile radio channel for smart rail mobility," IEEE Transactions on Vehicular Technology, vol. 66, no. 7, pp. 5658-5674, 2017.

[2] B. Ai, K. Guan, M. Rupp et al., "Future railway servicesoriented mobile communications network," IEEE Communications Magazine, vol. 53, no. 10, pp. 78-85, 2015.

[3] T. Zhou, H. Li, Y. Wang, L. Liu, and C. Tao, "Channel modeling for future high-speed railway communication systems: a survey," IEEE Access, vol. 7, pp. 52818-52826, 2019.

[4] P. Aikio, R. Gruber, and P. Vainikainen, "Wideband radio channel measurements for train tunnels," in Proceedings of the TC '98. 48th IEEE Vehicular Technology Conference. Pathway to Global Wireless Revolution, vol. 1, pp. 460-464, Ottawa, Canada, May 1998.

[5] L. Zhang, C. Briso, J. R. O. Fernandez et al., "Delay spread and electromagnetic reverberation in subway tunnels and stations," IEEE Antennas and Wireless Propagation Letters, vol. 15, pp. 585-588, 2016.

[6] J. Li, Y. Zhao, J. Zhang, R. Jiang, C. Tao, and Z. Tan, "Radio channel measurements and analysis at $2.4 / 5 \mathrm{GHz}$ in subway tunnels," China Communications, vol. 12, no. 1, pp. 36-45, 2015.

[7] C. Garcia-Pardo, J.-M. A. Molina-GarcÃ-a-Pardo, M. Lienard, D. P. Gaillot, and P. Degauque, "Double directional channel measurements in an arched tunnel and interpretation using ray tracing in a rectangular tunnel," Progress in Electromagnetics Research M, vol. 22, pp. 91-107, 2012.

[8] J. Zhao, L. Xiong, D. He, and J. Du, "channel characteristics of rail traffic tunnel scenarios based on ray-tracing simulator," Wireless Communications and Mobile Computing, vol. 2018, Article ID 9284639, 9 pages, 2018.

[9] S. K. Kalyankar, Y. H. Lee, and Y. S. Meng, "Two-slope path loss model for curved-tunnel environment with concept of break point," IEEE Transactions on Intelligent Transportation Systems, vol. 2020, Article ID 3012724, 10 pages, 2020.

[10] Y. Zhang, Y. Liu, J. Sun, C. Wang, and X. Ge, "Impact of different parameters on channel characteristics in a highspeed train ray tracing tunnel channel model," in Proceedings of the 2017 IEEE 85th Vehicular Technology Conference (VTC Spring), pp. 1-5, Sydney, NSW, Australia, June 2017.

[11] S.-D. Li, Y.-J. Liu, L.-K. Lin et al., "Channel measurements and modeling at $6 \mathrm{GHz}$ in the tunnel environments for $5 \mathrm{G}$ wireless systems," International Journal of Antennas and Propagation, vol. 2017, Article ID 1513038, 15 pages, 2017. 
[12] S. Choi, H.-S. Chung, D.-S. Cho et al., "Performance evaluation of millimeter-wave-based communication system in tunnels,", in Proceedings of the 2015 IEEE Globecom Workshops (GC Wkshps), pp. 1-5, San Diego, CA, USA, December 2015.

[13] D. He, B. Ai, K. Guan et al., "channel measurement, simulation, and analysis for high-speed railway communications in 5G millimeter-wave band," IEEE Transactions on Intelligent Transportation Systems, vol. 19, no. 10, pp. 3144-3158, 2018.

[14] X. Yin, X. Liu, G. Zheng, A. Saleem, and X. Zhai, " $28-\mathrm{GHz}$ channel characterization for a short tunnel," IEEE Microwave and Wireless Components Letters, vol. 28, no. 12, pp. 11461148, 2018.

[15] Y. Jiang, G. Zheng, X. Yin, A. Saleem, and B. Ai, "Performance study of millimetre-wave MIMO channel in subway tunnel using directional antennas," IET Microwaves, Antennas \& Propagation, vol. 12, no. 5, pp. 833-839, 2018.

[16] X. Liu, X. Yin, and G. Zheng, "Experimental investigation of millimeter-wave MIMO channel characteristics in tunnel," IEEE Access, vol. 7, pp. 108395-108399, 2019.

[17] G. Li, B. Ai, K. Guan et al., "Path loss modeling and fading analysis for channels with various antenna setups in tunnels at $30 \mathrm{GHz}$ band," in Proceedings of the 2016 10th European Conference on Antennas and Propagation (EuCAP), pp. 1-5, Davos, Switzerland, April 2016.

[18] G. Li, B. Ai, K. Guan et al., "Channel characterization for mobile hotspot network in subway tunnels at $30 \mathrm{GHz}$ band," in Proceedings of the 2016 IEEE 83rd Vehicular Technology Conference (VTC Spring), pp. 1-5, Nanjing, China, May 2016.

[19] T. Zhou, H. Li, R. Sun, Y. Wang, L. Liu, and C. Tao, "Simulation and analysis of propagation characteristics for tunnel train-ground communications at 1.4 and $40 \mathrm{GHz}$," IEEE Access, vol. 7, pp. 105123-105131, 2019.

[20] L. Xiong, H. Miao, B. Ai, T. Juhana, and A. Kurniawan, "Channel characteristics of high-speed railway station based on ray-tracing simulation at $5 \mathrm{G}$ mmWave band," International Journal of Antennas and Propagation, vol. 2019, Article ID 3137583, 10 pages, 2019.

[21] S. Suiyan Geng, J. Kivinen, X. Xiongwen Zhao, and P. Vainikainen, "Millimeter-wave propagation channel characterization for short-range wireless communications," IEEE Transactions on Vehicular Technology, vol. 58, no. 1, pp. 3-13, 2009.

[22] International Telecommunication Union, "Effects of building materials and structures on radiowave propagation above about $100 \mathrm{MHz}$," Recommendation ITU-R P.2040-1, pp. 22-23, 2015.

[23] S. Li, Y. Liu, L. Lin, M. Wang, Z. Sheng, and D. Sun, "Millimeter-wave propagation measurement and simulation in a indoor office environment at $28 \mathrm{GHz}$," in Proceedings of the 2017 Sixth Asia-Pacific Conference on Antennas and Propagation (APCAP), pp. 1-3, Xi'an, China, October 2017.

[24] S. Hur, S. Baek, B. Kim et al., "Proposal on millimeter-wave channel modeling for $5 \mathrm{G}$ cellular system," IEEE Journal of Selected Topics in Signal Processing, vol. 10, no. 3, pp. 454-469, 2016.

[25] T. Rappaport, Wireless Communications: Principles and Practice, Prentice Hall PTR, Hoboken, NJ, USA, 2002.

[26] Spatial channel model for multiple input multiple output (MIMO) simulations, "3rd Generation Partnership Project, Sophia Antipolis Cedex, France," Tech. Rep. TR 38.901, 2019.

[27] X. Cai, X. Yin, X. Cheng, and A. Pérez Yuste, "An empirical random-cluster model for subway channels based on passive measurements in UMTS," IEEE Transactions on Communications, vol. 64, no. 8, pp. 3563-3575, 2016. 